\section{Chrysotype: Photography in Nanoparticle Gold}

\section{Mike Ware}

20 Bath Road, Buxton, SK17 6HH, UK

e-mail: mike@mikeware.co.uk

\begin{abstract}
The printing of photographs in pure gold, rather than the ubiquitous medium of silver, was first achieved in 1842 by Sir John Herschel, but his innovative 'chrysotype' process was soon consigned to obscurity, owing to its expense and uncertain chemistry. In the 1980s some modern coordination chemistry of gold was applied to overcome the inherent problems, enabling an economic, controllable gold-printing process of high quality, which offers unique benefits for specialised artistic and archival photographic purposes. The colour of the gold image depends on the dimensions of the nanoparticles, which are controlled by the parameters of the photochemical process.
\end{abstract}

\section{Keywords}

nanoparticle gold, chrysotype, aurotype, alternative photographic printing, iron-based process, siderotype, photochemistry of iron(III), thioether complexes of gold(I), Sir John FW Herschel

\section{Introduction}

Gold has always played a role in photography as the ultimate means of stabilizing and protecting the silver image, the universal commercial medium. Since the dawn of the artscience of photography around 1840, a gold complex salt (1), sodium bisthiosulphatoaurate(I) was used to 'gild' the images of daguerreotypes by depositing gold metal on the surface of the silver:

$$
\mathrm{Ag}+\left[\mathrm{Au}\left(\mathrm{S}_{2} \mathrm{O}_{3}\right)_{2}\right]^{3-} \rightarrow \mathrm{Au} \downarrow+\left[\mathrm{Ag}\left(\mathrm{S}_{2} \mathrm{O}_{3}\right)_{2}\right]^{3-}
$$

In 1847, this was also recommended for the stabilization of silver photographic prints on paper. In this way, vulnerable silver images were protected from the sulphiding action of the polluted industrial atmospheres of the Victorian era, which otherwise caused them to tarnish or fade. From 1855 onwards, the gold toning of silver salted paper and albumen prints became standard practice, such that the British Government Photographer in India, Linnaeus Tripe, was moved to advise his colleagues "Not to spare the sovereigns!" (2). This important application of gold in photography has previously been reviewed in the Gold Bulletin by P Ellis (3).

But if gold is such a stable image substance, why not bypass the use of reactive silver altogether, and make photographs entirely in gold in the first place? Technically, there are difficulties: none has ever been usefully produced in the camera, owing to a much lower photochemical sensitivity of gold salts compared with the halides of silver, which can be uniquely 'fast' in development, providing us with near-instantanous negatives. Today, we owe the high speed of camera film emulsions to the use of $\operatorname{gold}(\mathrm{I})$ compounds as sensitizers for the silver halide grains (4).

Printing positives from the negatives, however, is less critical: exposures can be lengthy and light sources intense, especially if enlargers are not employed, which opens the door to using less sensitive photochemistry. The purpose of this review is to describe the chemical evolution of an economic and controlled process for photographic printing of pictures in pure gold in the nanoparticle state. The history of this process finds its origins in the dawn of photography, but it lay forgotten - until recent times - because it did not prove economic in the face of the competing metal, silver. In this account, the historical developments will be reinterpreted with the wisdom of hindsight, using modern chemical nomenclature, equations, and concepts, rather than the original nineteenth-century chemical language. For those readers who would like to see the original writings, which are sometimes cryptic and obscure, an historical review is recommended (5).

\section{Sir John Herschel's Chrysotype Process}

The announcement of the invention of silver photography on paper in January 1839, by William Henry Fox Talbot, inspired 
his colleague, Sir John Herschel to begin an energetic pursuit of a whole variety of potential photographic processes (6). Unlike Talbot, Herschel showed little interest in recording images in the camera; he was concerned with the photochemical effects of the optical spectrum on a wide range of substances, organic and inorganic, with the ultimate objective of trying to print permanent photographs in colour. In 1842, a young fellow-member of the Royal Society, Dr. Alfred Smee, introduced Herschel to a substance that had lately been attracting the attention of pharmacists as an iron tonic: ammonium iron(III) citrate. Herschel soon discovered that this salt was very sensitive to ultraviolet and blue light (7), and he recognised that the iron(III) was reduced photochemically (8) to iron(II):

$$
2 \mathrm{Fe}^{(I I I)}+\mathrm{C}_{6} \mathrm{H}_{8} \mathrm{O}_{7} \rightarrow 2 \mathrm{Fe}^{(I I)}+\mathrm{C}_{5} \mathrm{H}_{6} \mathrm{O}_{5}+\mathrm{CO}_{2} \uparrow+2 \mathrm{H}^{+}
$$

which could then react further to form permanent images in a variety of ways:

i) by coupling with hexacyanoferrate(III) to make Prussian blue, iron(III) hexacyanoferrate(II), as in Herschel's cyanotype process, which later assumed enormous commercial importance as the first reprographic process - for making blueprints:

$$
\mathrm{Fe}^{(I I)}+\left[\mathrm{Fe}^{(I I I)}(\mathrm{CN})_{6}\right]^{3-} \rightarrow \mathrm{Fe}^{(I I)}\left[\mathrm{Fe}^{(I I)}(\mathrm{CN})_{6}\right]^{-}
$$

ii) by reducing a salt of a noble metal to the metal, as in Herschel's argentotype (silver), celaenotype (mercury) and chrysotype (gold) processes:

$$
3 \mathrm{Fe}^{(\mathrm{II})}+\left[\mathrm{Au}^{(\mathrm{III})} \mathrm{Cl}_{4}\right]^{-} \rightarrow 3 \mathrm{Fe}^{(\mathrm{III})}+\mathrm{Au} \downarrow+4 \mathrm{Cl}^{-}
$$

iii) later in 1873 William Willis, using the same principle, reduced salts of platinum(II) or palladium(II) to the metals, but with iron(III) oxalate rather than citrate as the photosensitive component. This was the celebrated platinotype process, which became a great commercial and artistic success (9).

Herschel's chrysotype process did not win acceptance into the photographic repertoire, dashing his hopes, in the face of competition from Talbot's more tractable and less expensive silver processes, even though these suffered from acknowledged impermanence. What exactly was the problem with Herschel's chrysotype? His difficulties began with the photosensitive substance, ammonium iron(III) citrate, which is amorphous and uncrystallizable, and therefore of unknown structure even today; it displays a highly variable composition, with an iron content varying between 28\% and 14\%, depending on the method and conditions of preparation; it can be obtained in basic or acidic forms, varying in colour from brown to green. All in all, it is a highly 'ill-characterised', polymorphic, irreproducible substance! It appears that the variety available to Herschel was one of the 'brown' forms, which is basic, and easily liberates free citrate ions. Citrate is an excellent reductant for converting gold(III), as in $\left[\mathrm{AuCl}_{4}\right]^{-}$, to the metal, so the two components could not be pre-mixed without decomposition. Consequently, Herschel was obliged to coat his papers only with ammonium iron(III) citrate by itself, make the exposure, then 'develop' the picture by treating the sheet with a solution of sodium tetrachloroaurate(III), which, of course, became rapidly contaminated by the soluble substances leaching out of the sensitized paper. This was a very uneconomic and wasteful way to proceed, because it produced images of uncertain, and frequently inferior quality, at considerable expense. There was also an aesthetic difficulty at the time with photographic images that were not the conventional brown or black of silver and platinum in the finely-divided state; the reds and purples of nanoparticle gold photographs were an unacceptable shock to Victorian pictorial sensibilities.

\section{Later Attempts at Printing in Gold}

Throughout the nineteenth century, there were sporadic attempts to revive, improve, or re-invent, Herschel's chrysotype (10). Three of the more chemically interesting investigations of alternative methods of printing in gold deserve mention. Robert Hunt in 1844 found a mixture of silver nitrate with potassium dicyanoaurate(I), $\mathrm{K}\left[\mathrm{Au}(\mathrm{CN})_{2}\right]$, to be light-sensitive - the latter was prepared from fulminating gold and potasssium cyanide! - but it is uncertain how far the image was composed of gold, or of silver (11).

John Mercer around 1855 converted the Prussian blue of cyanotype images into Purple of Cassius (12) - the longcelebrated ceramicists' pigment, consisting of colloidal gold dispersed in tin(IV) hydroxide - its history has been fully described in this Journal (13). Mercer first converted the iron(III) hexacyanoferrate(II) into silver hexacyanoferrate(II) by treatment with silver nitrate, after which he reduced it to silver metal by sodium stannite, $\mathrm{Na}_{2}\left[\mathrm{SnO}_{2}\right]$, and finally by treating this in a bath of sodium tetrachloroaurate(III), the Purple of Cassius was precipitated.

Charles Burnett in 1857 employed photosensitive salts of uranium(VI), instead of iron(III), to make images in gold (14):

$$
\begin{gathered}
\mathrm{UO}_{2}{ }^{2+}+2 \mathrm{e}^{-}+4 \mathrm{H}^{+} \rightarrow \mathrm{U}^{4+}+2 \mathrm{H}_{2} \mathrm{O} \\
3 \mathrm{U}^{4+}+2\left[\mathrm{AuCl}_{4}\right]^{-}+6 \mathrm{H}_{2} \mathrm{O} \rightarrow 3 \mathrm{UO}_{2}^{2+}+2 \mathrm{Au} \downarrow+4 \mathrm{H}^{+}+8 \mathrm{HCl}
\end{gathered}
$$

The only significant improvement in the chrysotype process itself arose in 1897 when a 'green' form of ammonium iron(III) citrate was first prepared (15), which was less reactive towards tetrachloroaurate(III) and could be pre-mixed with it before coating, but the outcome was seldom pictorially acceptable (16). In contrast to the equally costly platinotype process, which proved highly reliable, the expense of frequent failure with the chrysotype medium precluded it 
from general use. It was deemed inadequate, and by the close of the century, gold had been totally written off as an imaging substance per se, nothwithstanding its widespread continuing use to tone and protect silver photographs.

\section{An Update on Iron(III) Photochemistry}

In the course of a research programme to up-date the nineteenth-century iron-based photographic printing processes (17), collectively called 'siderotypes' (18), it was noted that a much better photosensitive iron(III) salt for this purpose is ammonium trisoxalatoferrate(III), $\left(\mathrm{NH}_{4}\right)_{3}\left[\mathrm{Fe}\left(\mathrm{C}_{2} \mathrm{O}_{4}\right)_{3}\right] \cdot 3 \mathrm{H}_{2} \mathrm{O}$, which had been employed occasionally since the 1850s (19). This is a well-characterised complex salt, obtainable analytically pure, crystalline, and of known structure (a simple tris-chelate of bidentate oxalate groups, the donor oxygen atoms being disposed approximately octahedrally around the iron). The photochemistry yields a soluble iron(II) oxalato-complex:

$$
\mathrm{h} v+2\left[\mathrm{Fe}^{(I I I)}\left(\mathrm{C}_{2} \mathrm{O}_{4}\right)_{3}\right]^{3-} \rightarrow 2\left[\mathrm{Fe}^{(I I)}\left(\mathrm{C}_{2} \mathrm{O}_{4}\right)_{2}\right]^{2-}+2 \mathrm{CO}_{2} \uparrow+\mathrm{C}_{2} \mathrm{O}_{4}{ }^{2-}
$$

For UVA light of wavelength $365 \mathrm{~nm}$, the quantum yield for this process in aqueous solution is 1.26 moles of iron per einstein, about four times that of the citrate. The quantum yield falls off sharply in the green region of the visible spectrum, and is zero at longer wavelengths. This reaction is accompanied by only a slight colour change in the material, from pale yellow-green to pale yellow-brown; moreover this change is temporary, because the iron(II) is slowly re-oxidised back to iron(III) by oxygen in the air:

$$
4 \mathrm{Fe}^{(I I)}+\mathrm{O}_{2}+2 \mathrm{H}_{2} \mathrm{O} \rightarrow 4 \mathrm{Fe}^{(I I I)}+4 \mathrm{OH}^{-}
$$

In order to make a permanent photograph, the iron(II) which is formed by the action of light must be immediately reacted to produce a more visible and enduring substance for the image. Chemically, the resulting iron(II) complex is quite a strong reducing agent, as may be seen from its redox potential:

$$
\mathrm{E}^{\mathrm{O}}\left(\left[\mathrm{Fe}\left(\mathrm{C}_{2} \mathrm{O}_{4}\right)_{3}\right]^{3-} /\left[\mathrm{Fe}\left(\mathrm{C}_{2} \mathrm{O}_{4}\right)_{2}\right]^{2-}\right)=+0.02 \mathrm{~V}
$$

One option is to use it to reduce the compounds of 'noble' metals, such as platinum, palladium, silver or gold, to the metallic state, which then constitutes the final image, e.g.:

$$
\left[\mathrm{AuCl}_{4}\right]^{-}+3\left[\mathrm{Fe}\left(\mathrm{C}_{2} \mathrm{O}_{4}\right)_{2}\right]^{2-} \rightarrow \mathrm{Au} \downarrow+3\left[\mathrm{Fe}\left(\mathrm{C}_{2} \mathrm{O}_{4}\right)_{2}\right]^{-}+4 \mathrm{Cl}^{-}
$$

This is the general chemical principle underlying the historical 'iron-based' alternative printing processes in gold, silver, mercury, platinum and palladium (20), which correspond respectively to Herschel's original chrysotype, argentotype and celaenotype all of which used ammonium iron(III) citrate as the photosensitive component, and to the later platinotype and palladiotype processes due to Willis (21), which used iron(III) oxalate. However, this second, imageforming reaction does not take place in the dry sensitized layer on paper, because the molecule-ions cannot encounter one-another. They only achieve the necessary mobility if there is some water present in the fibres; they can then migrate locally and react to form nanoparticles of noble metal which are trapped in the paper to constitute the final image. If the sensitized layer is very dry, this water will only be supplied when the sheet is immersed in the first processing solution, and the image will appear to be 'developed'. However, if the sensitized paper is not fully dried, but allowed to acquire a controlled degree of humidity prior to exposure, the gold image will form during the exposure in a printing-out process, and may require little or no subsequent development.

The chief difficulty in applying the iron-based photochemical system to printing in gold arises from the strongly oxidising nature of the most commonly available gold compounds, salts of the tetrachloroaurate(III) anion, for which the redox potential is:

$$
\mathrm{E}^{\mathrm{O}}\left(\left[\mathrm{AuCl}_{4}\right]^{-} / \mathrm{Au}, 4 \mathrm{Cl}^{-}\right)=+1.00 \mathrm{~V}
$$

This redox potential is high enough to cause oxidation of the carboxylate anion, citrate or oxalate, which would be present in the mixed sensitizer, with consequent premature deposition of gold metal, as Herschel originally discovered. It became apparent that a viable gold printing process would require that the oxidising power of the gold salt be diminished, so that it did not decompose thermally in the presence of citrate or oxalate, thus:

$$
2\left[\mathrm{AuCl}_{4}\right]^{-}+3 \mathrm{C}_{2} \mathrm{O}_{4}^{2-} \rightarrow 2 \mathrm{Au} \downarrow+6 \mathrm{CO}_{2} \uparrow+8 \mathrm{Cl}^{-}
$$

It would also be advantageous to the quantum efficiency of the process if the gold could be in the form of gold(I) rather than gold(III), so establishing a more favourable 1:1 stoicheiometry vis à vis the iron(II) reductant.

\section{Coordination chemistry of gold(I)}

Clearly the solution to these problems lay in finding a suitable compound, preferably of gold(I), having a diminished redox potential with respect to the metal so that it could tolerate the presence of oxalate. Most simple binary compounds of gold (I) in an aqueous environment are unstable with respect to disproportionation into the metal and gold(III):

$$
3 \mathrm{Au}^{(l)} \rightarrow 2 \mathrm{Au}^{(0)}+\mathrm{Au}^{(\mathrm{III})}
$$

so it is necessary to seek the answer among the complexes of gold(I). Until fairly recently, the only well-known watersoluble, stable gold(I) complexes were, typically, the sulphito-, cyano-, thiocyanato-, and thiosulphato- species, $\left[\mathrm{Au}\left(\mathrm{SO}_{3}\right)_{2}\right]^{3-}$, 
$\left[\mathrm{Au}(\mathrm{CN})_{2}\right]^{-}, \quad\left[\mathrm{Au}(\mathrm{SCN})_{2}\right]^{-}$and $\left[\mathrm{Au}\left(\mathrm{S}_{2} \mathrm{O}_{3}\right)_{2}\right]^{3-}$, respectively. But these complexes have such large formation constants that the redox potential is depressed to values below even that of the iron(II) photoproduct, e.g:

$$
\mathrm{E}^{\mathrm{O}}\left(\left[\mathrm{Au}(\mathrm{CN})_{2}\right]^{-} / \mathrm{Au}, 2 \mathrm{CN}^{-}\right)=-0.6 \mathrm{~V}
$$

so they cannot be reduced to gold metal by bisoxalatoferrate(II).

The first objective of this work was therefore to find a soluble gold(I) complex of intermediate stability: to this end, many potential ligands were tested by reacting them with tetrachloroaurate(III), then mixing the product with ammonium trisoxalatoferrate(III) solution to see if a suitable sensitizer resulted according to the following criteria (22):

i) The ligand should form a gold(I) complex that is thermally stable in aqueous solution, but reducible to the metal by the iron(II) photoproduct.

ii) The ligand should not cause precipitation of an insoluble gold complex at the high concentrations (ca. $0.3 \mathrm{M}$ ) needed to give adequate coating weight when imbibed into paper.

iii) The ligand and its gold(I) complex should not react significantly with the trisoxalatoferrate(III) anion.

iv) The ligand should not be malodorous or highly toxic.

v) The mixed sensitizer should be stable for at least ten minutes under ambient conditions, to allow coating of paper without perceptible precipitation of gold.

vi) Exposure to UVA (365 nm) light of the sensitized paper in contact with a photographic step tablet should yield a well-graduated print of long tonal scale, smooth texture, a high maximum optical density, and no chemical fog after appropriate wet processing.

Ultimately, a ligand satisfying all these criteria was found: viz., 3,3'-thiodipropanoic acid, $\mathrm{S}\left(\mathrm{CH}_{2} \mathrm{CH}_{2} \mathrm{COOH}\right)_{2}$, used in the neutralised form of its disodium or diammonium salts, which are highly soluble in water. The reaction of this ligand with tetrachloroaurate(III) follows a path already well-established for other thioethers by Cattalini and co-workers (23). The generality of this reaction has also enabled McAuliffe and colleagues to devise a synthesis for neutral gold(I) complexes that are water insoluble and therefore readily isolated and characterised (24). Kinetic studies show that the reaction mechanism takes place in two steps, as follows (25) (for brevity the ligand formula will be written here as $\mathrm{SR}_{2}$ ):

i) Coordination of the ligand with tetrachloroaurate(III), displacing chloride:

$$
\left[\mathrm{AuCl}_{4}\right]^{-}+\mathrm{SR}_{2} \rightarrow\left[\mathrm{AuCl}_{3} \mathrm{SR}_{2}\right]+\mathrm{Cl}^{-}
$$

ii) Attack of a second molecule of ligand on the gold(III) complex, reducing it to a two-coordinate gold(I) complex, the thioether ligand being itself oxidised in the presence of water to the corresponding sulphoxide:

$\left[\mathrm{AuCl}_{3} \mathrm{SR}_{2}\right]+\mathrm{SR}_{2}+\mathrm{H}_{2} \mathrm{O} \rightarrow\left[\mathrm{AuClSR}_{2}\right]+\mathrm{OSR}_{2}+2 \mathrm{H}^{+}+2 \mathrm{Cl}^{-}$
It is believed that this reductive step may take place via transfer of a chlorine atom from gold to sulphur, followed by hydrolysis.

iii) In the presence of excess ligand, an equilibrium is also possible, in which a third molecule of the ligand may displace the chloride ion from the gold(I) complex:

$$
\left[\mathrm{AuClSR}_{2}\right]+\mathrm{SR}_{2}=\left[\mathrm{Au}\left(\mathrm{SR}_{2}\right)_{2}\right]^{+}+\mathrm{Cl}^{-}
$$

These equations illustrate the reaction steps in a formalised manner only; the precise species present, and the states of ionization of the carboxylate functions at equilibrium, will obviously depend on the cation, $\mathrm{pH}$, and metal/ligand ratio. The speciation in this system is complex, and its investigation is hindered by the fact, apparent from the ${ }^{13} \mathrm{C} \mathrm{nmr}$ spectrum, that the ligand exchange processes of the labile $\mathrm{Au}(\mathrm{I})$ complexes are rapid (26).

\section{The New Chrysotype Process}

In summary, the new chrysotype process requires three stock solutions for mixing the sensitizer (27): The following concentrations were found convenient:

A. Ligand: a 1.4 M solution of the disodium or diammonium salts of 3,3'- thiodipropanoic acid

B. Gold: a $0.35 \mathrm{M}$ solution of sodium or ammonium tetrachloroaurate(III)

C. Iron: a 1.4 M solution of ammonium trisoxalatoferrate(III) These are mixed just before coating the paper substrate, typically in the volume ratios:

\section{$A: B: C=4: 4: 1$}

Although the ratios may be varied between $2: 4: 1$ and 6 : $4: 1$, where the first number represents the molar ratio of ligand : gold. Differing image contrast was found to result from varying this parameter. The aqueous solution of sodium or ammonium tetrachloroaurate(III) is added slowly, with cooling if necessary, to an excess of a concentrated solution of the disodium or diammonium salt of 3,3'-thiodipropanoic acid (potassium is avoided as a cation owing to the low solubility of potassium trisoxalatoferrate). The greater excess of ligand provides a more stable sensitizer and a higher contrast, but lower maximum optical density. The ammonium trisoxalatoferrate(III) solution is added next, with iron equimolar to the gold. It will be noted from the equations above, that the system becomes acidic as a consequence of the oxidation of the ligand, so the $\mathrm{pH}$ can be raised finally, if desired, with an appropriate alkali, but should not be allowed to rise above $\mathrm{pH}$ 7, to avoid undue hydrolysis of the iron(III) complex. The carboxylate functions of the ligand, having a $\mathrm{pk}_{\mathrm{a}}$ of ca. 4, also tend to provide an internal buffer action in this respect. To furnish an adequate coating weight of gold in the sensitizer solution, its final concentration should be ca. $0.15 \mathrm{M}$. 
The substrate usually chosen (for aesthetic rather than scientific reasons) is a pure cellulose paper, with no additives other than a sizing agent to control the absorptivity and restrict the imaging substance to the surface layer of fibres. Paper internally sized with 'Aquapel' (an alkyl ketene dimer) is suitable for neutral, blue or violet tones; but to achieve a good red colour the best paper sizing agent is gelatin, which 'protects' the smallest gold nanoparticles against flocculation. It is also possible that the gelatin enters into the sensitizer chemistry by binding with gold(I) via its sulphurcontaining aminoacid residues (28) such as cysteine (29) or methionine. The most suitable type of gelatin for this purpose was found to be a non-oxidised, de-ionised ossein; adsorption onto the gold hydrosol is most efficient at a $\mathrm{pH}$ near to the isoelectric point (pl) of the protein (30).

\section{The Practice of New Chrysotype}

Owing to the low sensitivity of the coating to visible radiation, photographic darkroom conditions are unnecessary for preparing and handling the sensitized paper, and an adequate 'safelight' is provided by a $60 \mathrm{~W}$ tungsten filament lamp distant two metres or more. Techniques for coating paper, which must be of the highest quality cellulose, and the rest of the contact printing manipulations are fully described on the WWW and in The Chrysotype Manual (27). As iron(III) carboxylates are sensitive only to the ultraviolet and bluegreen portions of the spectrum, exposure to a UVA light source is more controllable and convenient than to the sun, especially for those of us who are not blessed with a perfect climate! Typically, a source delivering a UVA flux of ca. 50 $\mathrm{W} / \mathrm{m}^{2}$ will require a contact exposure of a minute or two. Exposure has to be by contact with a large negative, in order to maximise the light throughput; conventional photographic enlargers are ineffective.

Reaction between the iron(II) photoproduct and the gold(I) complex takes place rapidly within hydrated regions of the cellulose structure during the exposure; the extent of 'print-out' of the image is consequently dependent on the relative humidity $(\mathrm{RH})$ of the paper's environment, being almost complete when this is high (RH ca. 80\%), but under dry conditions ( $\mathrm{RH}$ ca. 20\%) the 'print-out' is slight and the image undergoes extensive development during the wet processing.

Image colour and the extent of 'print-out' are therefore controlled by adjusting the humidity of the sensitized paper, before exposure, by equilibrating it in an enclosure of constant, known relative humidity, which is readily achieved by making use of saturated solutions of various salts. Pink and red images are obtained at low values ( $\mathrm{RH}=20-40 \%$ ), proceeding via purple to green, blue and neutral grey at high humidity (RH = 70-90\%). Paper exposed at low RH, when the print-out is slight, may be 'steam' developed simply by a short humidification over a water-bath held at $40-45^{\circ} \mathrm{C}$ (or even by breathing heavily upon it!). After exposure, the print is processed in a sequence of aqueous baths to dissolve out excess sensitizer reagents and residues, leaving only the gold nanoparticles embedded in the surface fibres of the pure cellulose substrate. The first processing bath should be prepared on a 'one shot' basis, because a re-used bath will build up a concentration of red gold sol which may stain the paper of subsequent prints. This 'developer' consists of a fresh solution of a ligand for iron(III) at a strength of ca. 1\% and an acidic pH ca. 4 : tartaric, citric or oxalic acid or disodium EDTA (disodium 1,2-diaminoethanetetraethanoate) all work well, and each of these reagents yields a slightly different colour in the gold image. Partial print-out followed by development can lead to artistically interesting 'split-tone' effects, in which the colour of the image varies across the optical density scale. The remaining clearing baths (which may be re-used) are intended to remove the final traces of excess gold and iron salts from the paper fibres. The entire processing procedure may be summarised as follows:

i) (Optional) 'steaming' over a warm $40^{\circ} \mathrm{C}$ water bath for 2 to 5 minutes.

ii) Develop in a solution ca. $1 \% \mathrm{w} / \mathrm{v}$ of disodium EDTA, tartaric, citric or oxalic acid, for 2 to 5 minutes. This bath should not be much re-used.

iii) 5\% tetrasodium EDTA \# 1.

iv) $2 \%$ sodium sulphite or metabisulphite

v) $5 \%$ tetrasodium EDTA \# 2 .

vi) Water wash for 30 to 60 minutes.

An immersion time in the clearing baths (iii) - (v) of about 10 minutes each seems adequate to remove all iron(III) and gold salts from the paper, to levels below detection by chemical spot tests. The sulphite reduces the iron(III) to iron(II), and forms strong, and relatively stable, soluble gold(I) complexes (31). Tetrasodium EDTA at high $\mathrm{pH}$ is an effective chelate for iron(II). All these baths have a pH ca. 9, which is beneficial to the long term stability of the cellulose paper substrate.

\section{Coloured Photographic Images in Nanoparticle Gold}

The identity of the image substance, obtained by the above procedure, as pure gold has been confirmed by $\mathrm{X}$ ray fluorescence spectrometry (32) : see Figure 1. Moreover, the nanoparticulate nature of the gold has been demonstrated in situ by high-resolution electron microscopy of new chrysotype prints (33): see Figure 2.

The chief characteristics of a chrysotype stem from the absence of any colloidal binder layer; unlike the silvergelatin print, it is viewable at any angle without reflective glare, and the texture of the paper surface is visible, and imparts a tactile quality to the image. These are also the characteristics of the platinum print, so what does the chrysotype process have to offer that cannot be provided by the well-established sister-processes on plain paper, platinotype and palladiotype, which can also boast 


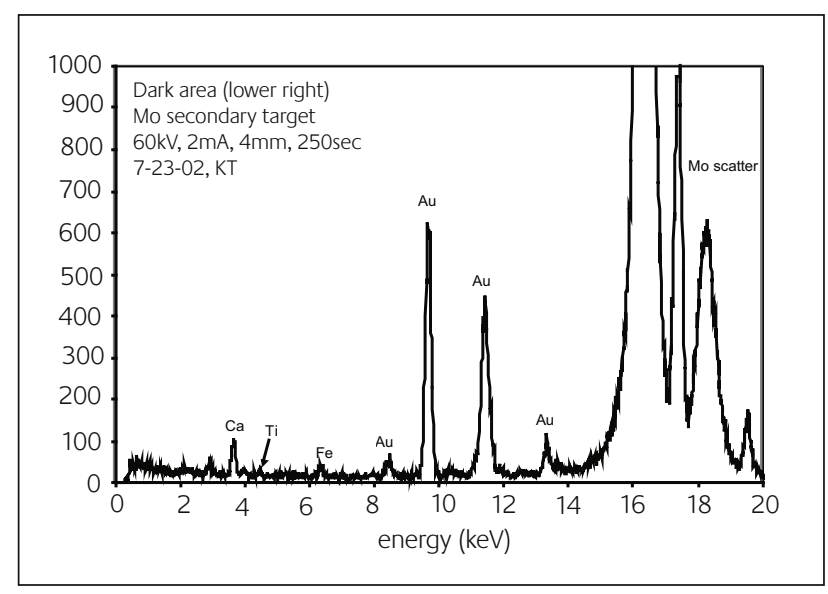

\section{Figure 1}

$X$-ray fluorescence spectrum of a new chrysotype print by the author. The spectrum clearly shows the strong presence of Au as the image substance, with $\mathrm{Ca}$, Fe and $\mathrm{Ti}$ as minor components that are also present in the paper substrate. The large peaks at the right side of the spectrum are scatter peaks from the Mo secondary target. Courtesy of Dr. Karen Trentelman, Conservation Department, The Detroit Institute of Arts, Michigan

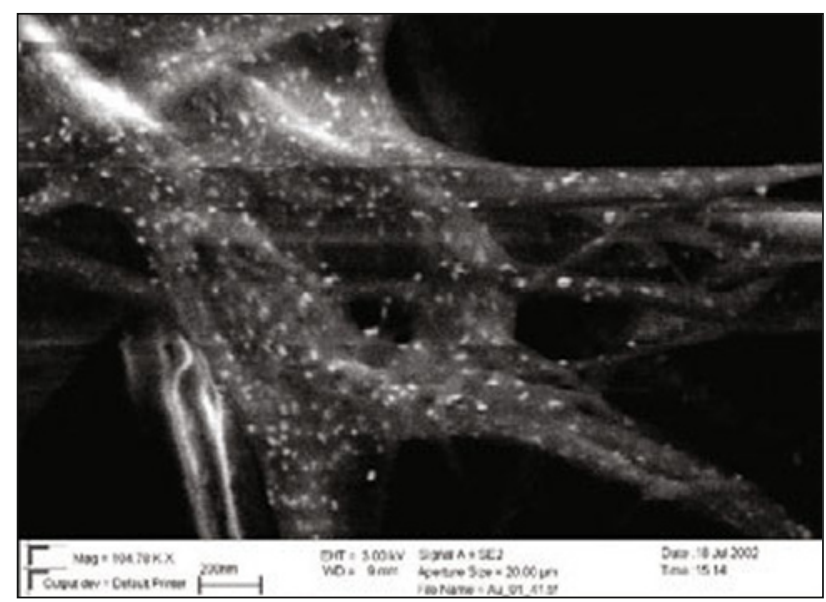

Figure 2

Scanning electron micrograph of a new chrysotype print by the author x105,000 showing cellulose microfibrils with gold nanoparticles in situ. Courtesy of Dr. Sharali Malik, Institut für Nanotechnologie, Karlsruhe, Germany

comparable archival permanence? The answer, in one word, is: 'colour'. What was regarded as a defect of gold images in the nineteenth century, is today viewed as an expansion of the expressive boundaries of the photographic art. The colour of the chrysotype as a pictorial medium is non-literal, or even surreal, and offers an extra dimension for the artist to explore. Cold is unique among metals for the range of colour it can display in the nanoparticle state.

Since Michael Faraday's investigations, described in his Bakerian lecture (34) of 1857, the optical properties of gold 'colloids' have attracted much attention. The state of dispersion of gold sols determines their optical spectra in a way that is now well-understood: the theoretical basis for the relationship of the colours of nanoparticle metal to particle size, shape, and state of aggregation has been discussed

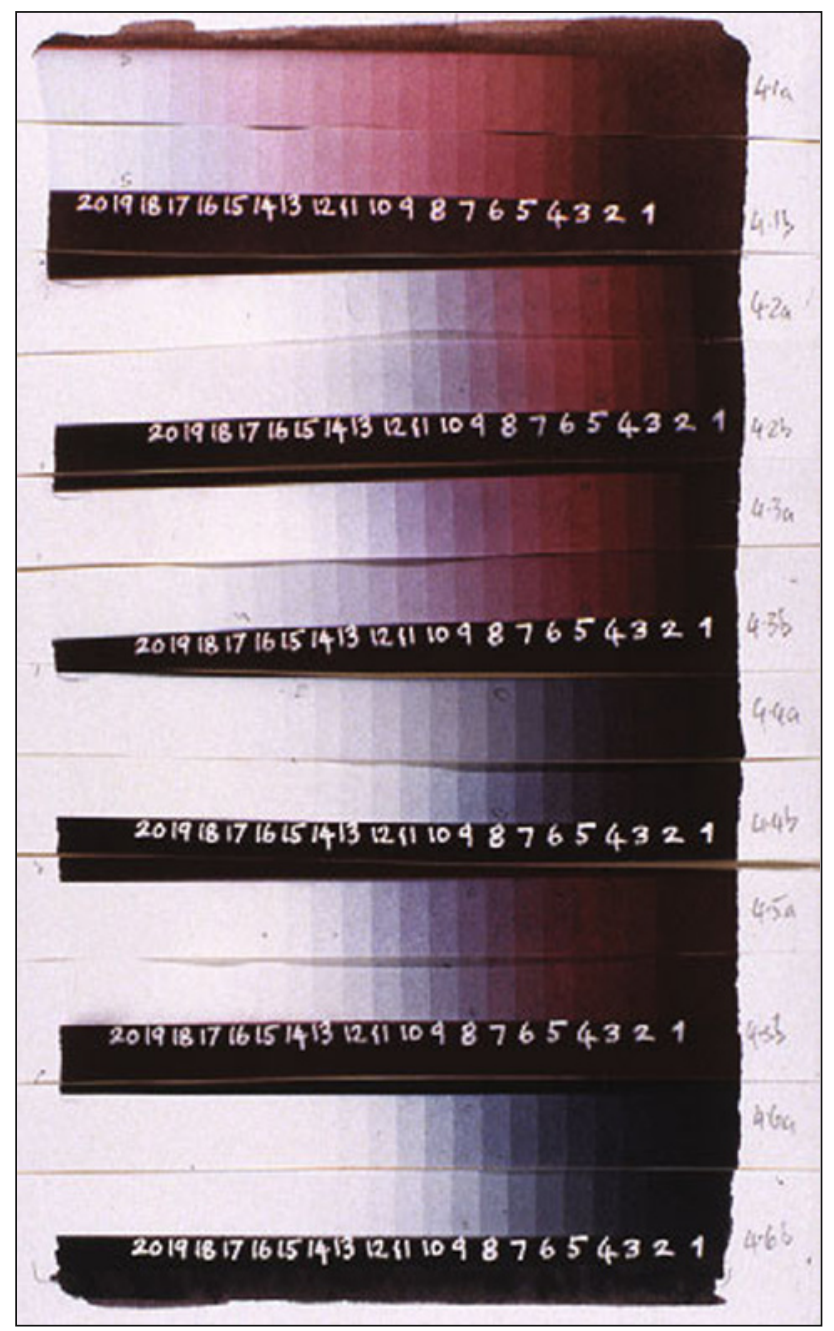

Figure 3

Step tablet test $(\Delta D=0.15)$ of a typical new chrysotype sensitizer solution. The Relative Humidity of the tests increases from top ( $9 \%$ RH) to bottom (85\% RH)

extensively elsewhere in terms of Mie theory (35), and there have been many experimental investigations of gold sols by electron microscopy, in which the absorption spectrum is correlated with particle size and shape, as summarised in Table 1 (36).

Figure 3 shows a typical step tablet test of a new chrysotype sensitizer, illustrating some of the range of colour obtainable and its dependence upon humidity.

\section{Table 1}

Colour and particle size of gold nanoparticles

\begin{tabular}{|c|c|c|}
\hline Shape & Size/nm & Colour \\
\hline \multirow[t]{6}{*}{ Spherical } & $<3$ & Pale blue \\
\hline & 12 & Pink \\
\hline & 16 & Orange \\
\hline & $20-40$ & Red \\
\hline & 70 & Dark magenta \\
\hline & $100-150$ & Violet \\
\hline Irregular & 200 & Light Blue \\
\hline Ellipsoids & $60 \times 90$ & Purple \\
\hline Aggregated & & Blue \\
\hline
\end{tabular}




\section{Future Prospects for Chrysotype}

In the new chrysotype process, the colour of the image may be controlled over a considerable range by varying the humidity, $\mathrm{pH}$, and composition of the sensitizer, and the developer and paper sizing agent. For practical purposes, a good magenta and a passable cyan are obtainable with gold, but as yet yellow gold nanoparticles have not been obtained: this unfortunately diminishes the rather attractive possibility of a three-colour printing process which uses no pigment other than pure nanoparticle gold.

The covering power, $\mathrm{C}$, of an imaging substance is customarily defined as $C=D / M$, where $D$ is the optical density (in this case measured in diffuse reflectance) and $M$ is the coating weight in mass of metal per unit area. Owing to the small particle size, values of $C$ are higher $\left(c a .5 \mathrm{~m}^{2} / \mathrm{g}\right)$ for nanoparticle gold than for silver, palladium and platinum (ca. $1 \mathrm{~m}^{2} / \mathrm{g}$ ) which compensates somewhat for its high cost as an imaging material. The extremely small image particle size (ca. 10-40 nm) also suggests that nanoparticle gold images may have considerable potential as a medium for permanent information storage purposes, but it will require a substrate much more homogeneous than paper, if full advantage is to be taken of the high resolution. With slight modifications to the chemistry, it may be possible to prepare gold sensitizers in solutions containing gelatin, PVA, or other colloidal binder, which can then be coated onto glass plates or plastic film. Alternatively, the aqueous sensitizer solution can be very satisfactorily imbibed into the zeolytic coatings now available on the transparency materials intended for ink-jet printers.

An increase in effective photographic 'speed' of this process is observed when the ligand-to-gold ratio in the sensitizer is low, giving a more labile gold(I) complex, which suggests that the gold nanoparticles may be capable of growing by 'physical development', akin to the process of selective gold deposition from 'electroless' autocatalytic plating baths (37). If a sufficiently stable latent image in gold at the smallest particle size can be formed, and subsequently grown from these 'nuclei', it is possible that a 'projectionspeed' material could be devised, to avoid the need for contact-printing.

It has already been stated that chrysotype resembles the better-known, and at one time widely acclaimed, platinotype process (38). New chrysotypes are extremely light-fast and resistant to chemical attack; they therefore enjoy an archival permanence at least equalling, and perhaps surpassing, that of the platinotype. The conservatorial problem which has beset all historic platinotypes arises from the high catalytic activity of platinum black, which can bring about the aerial oxidation of $\mathrm{SO}_{2}$ to $\mathrm{SO}_{3}$, thus causing serious acid embrittlement of the paper base by sulphuric acid formed in situ. In contrast to platinum, nanoparticle gold has a very low catalytic activity in this respect (39), so this problem should be absent from chrysotypes. The longevity of the paper substrate will also be enhanced by the alkaline conditions of the wet processing, in contrast to the hydrochloric acid clearing baths sometimes used to process platinotypes.

The closing decade of the twentieth century saw the onset of a revolution in the imaging technology that underpins the lens-based media: the core science underwent a wholesale displacement, from chemistry to physics. Analogue imaging by photochemical reactions is now rapidly giving way commercially to the digital recording of a stream of photoelectronic signals. The traditional processes of the photographic darkroom are now being displaced by the convenient functionality of the desktop computer, and the commercially-produced silver-gelatin photographic negative is being replaced by the string of binary code. Increasingly, photographic images are being stored as digital files, but many of these may prove ephemeral, because the long-term stability and accessibility of this information is not yet technically guaranteed. If there is to be a future place in our culture for paper photographs - as flat objects, easily handled and humanly readable, enduring for a millennium independent of the state of computer technology - then nanoparticle gold could provide such a medium.

\section{About the author}

Mike Ware graduated in chemistry in 1962 at the University of Oxford, where he subsequently obtained his D.Phil. in molecular spectroscopy. Following a career of teaching and research in structural and inorganic chemistry at the University of Manchester (1964-92), he committed himself to the independent study of the science, history, art and conservation of alternative photographic processes. His researches on printing in noble metals were awarded the Hood Medal of the Royal Photographic Society in 1990. He consults for the National Museum of Photography, Film \& Television, and has supervised postgraduate research at the Victoria \& Albert Museum and the Royal College of Art. His books, Mechanisms of Image Deterioration in Early Photographs (1994) and Cyanotype: the History, Science and Art of photographic printing in Prussian Blue (1999), were published by the Science Museum, London, and his latest monographs are Gold in Photography and The Chrysotype Manual (2006). He exhibits and lectures on his personal photographic work in the USA and Europe.

\section{Notes and References}

$1 \mathrm{Na}_{3}\left[\mathrm{Au}\left(\mathrm{S}_{2} \mathrm{O}_{3}\right)_{2}\right]$, prepared by the addition of sodium tetrachloroaurate(III) solution to excess sodium thiosulphate, was called 'Fordos' and Gelis' salt', after its discoverers

2 Which were dissolved in aqua regia to provide a solution of tetrachloroaurate(III)

3 P. Ellis, Gold Bulletin, 1975, 8, 7

4 J.C. Deaton and H.R. Luss, J. Chem. Soc. (Dalton Trans.), 1999, 3163

5 M. Ware, History of Photography, 2006, 30, 1; see also M. Ware, Gold in Photography, ffotoffilm publishing, 2006 
6 For a history of early photography see: L.J. Schaaf, Out of the Shadows: Herschel, Talbot and the Invention of Photography, Yale University Press, New Haven \& London, 1992

7 Sir J.F.W. Herschel, Phil. Trans. Roy. Soc., 1842, 181

8 The citrate is now known to be oxidized with decarboxylation, to form acetone dicarboxylic acid in the first place. The photoactive citrato complex of $\mathrm{Fe}(\mathrm{III})$ is probably a dimeric species; see H.B. Abrahamson, A.B. Rezvani, and J.G. Brushmiller, Inorg. Chim. Acta, 1994, 226, 117

9 M. Ware, Platinum Metals Rev., 2005, 49, 190 http://www.platinummetalsreview.com/dynamic/article/view/49-4190-195

10 M. Ware, loc. cit., ref. 5

11 R. Hunt, Researches on Light, Longman, Brown and Green, London, 1844

12 M. Ware, Cyanotype, Science Museum, London, 1999

13 L.B. Hunt, Gold Bulletin, 1976, 9, 134 http://www.goldbulletin.org/downloads/Hunt_4_9.pdf

14 C.J. Burnett, Photogr. Notes, 1857, 2, 175

15 E. Valenta, Photogr. Corr., 1897, 74

16 A.J. Jarman, Amer. Amat. Phot., 1911, 5, 722

17 M. Ware, in Photochemistry and Polymeric Systems, eds. J.M. Kelly, C.B. McArdle and M.J. Maunder, R.S.C. Special Pub. No. 125, 1993, 252

18 This useful collective noun, due to Herschel, comes from the Greek for iron: sideros

19 M. Ware, J. Photogr. Sci., 1986, 34, 13

20 For more on the chemistry of noble metal printing, see M. Ware, op. cit., ref. 17 http://www.mikeware.co.uk

21 William Willis, British Patents, Nos. 2011 (June 1873), 2800 (July 1878), 1117 (March 1880). See also: L. Nadeau, History and Practice of Platinum Printing, 3rd edn., Atelier L. Nadeau, Fredericton, New Brunswick, Canada, 1994

22 M. Ware, J. Photogr. Sci., 1994, 42, 157

23 E. Bordignon, L. Cattalini, G. Natile, and A. Scatturin, J. Chem. Soc., Chem. Comm., 1973, 878; G. Natile, E. Bordignon, and L. Cattalini, Inorg. Chem., 1976, 15, 246
24 A.K. Al-Sa'ady, C.A. McAuliffe, R.V. Parish, and J.A. Sandbank, Inorganic Syntheses, 1983, 23; C.A. McAuliffe, R.V. Parish, and P.D. Randall, J. Chem. Soc., Dalton Trans., 1979, 1730

25 A. Annibale, L. Canovese, L. Cattalini, and G. Natile, J. Chem. Soc., Dalton Trans., 1980, 1017

26 Tanya Hughes and M. Ware, unpublished observations, 1989

27 Full instructions can be found in Mike Ware, The Chrysotype Manual, ffotoffilm publishing, 2006. http://www.ffotoffilm.co.uk

28 J.M. Harbison and H.E. Spencer, in The Theory of the Photographic Process, edited by T.H. James, 4th Edition, Macmillan, New York, 1977, 155

29 D.H. Brown, G.C. McKinley, and W. Ewen Smith, J. Chem. Soc. Dalton Trans., 1978, 199

30 S.L. Goodman, G.M. Hodges, L.K.Trejdosiewicz, and D.C. Livingston, J. Microscopy, 1981, 123, 201

31 P.C. Hydes and H. Middleton, Gold Bulletin, 1979, 12, 90

32 K. Trentelman, Detroit Institute of Arts, Michigan, private communication courtesy of $\mathrm{V}$. Baas

33 S. Malik, Institut für Nanotechnologie, Karlsruhe, private communication

34 M. Faraday, Phil. Trans. Roy. Soc., 1857, 147, 145

35 M. Kerker, The Scattering of Light and Other Electromagnetic Radiation, Academic Press, 1969; M. Kerker, J. Colloid Interface Sci., 1985, 105, 297; J.A. Creighton and D.C. Eadon, J. Chem. Soc. Faraday Trans., 1991, 87, 3881

36 J. Turkevich, P.C. Stevenson, and J. Hillier, Disc. Faraday Soc., 1951, 11, 55; R.M. Wilenzick, D.C. Russell, R.H. Moriss, and S.W. Marshall, J. Chem. Phys., 1967, 47, 533; G. Frens, Nature Phys. Sci., 1973, 241,20

37 W.S. Rapson and T. Groenewald, Gold Bulletin, 1975, 8, 119

38 M. Ware, 'The Eighth Metal: the Rise of the Platinotype Process', in Photography 1900, edited by J. Lawson, R. McKenzie and A.D. Morrison-Low, National Museums of Scotland, 1994 http://www.mikeware.co.uk/mikeware/Eighth_Metal.html

39 J. Turkevich, Gold Bulletin, 1985, 18, 125 